\title{
Study of Impressed Current Cathodic Protection (ICCP) on the Steel Pipeline under DC Stray Current Interference
}

\author{
Yong Guo ${ }^{1,2}$, Jifeng Ding ${ }^{1,2}$, Xiangyang $\mathrm{Li}^{3,{ }^{*}}$ and Jiarun $\mathrm{Li}^{4, *}$ \\ ${ }^{1}$ Central Iron and Steel Research Institute, Beijing 100081, China; \\ ${ }^{2}$ Qingdao NCS Testing and Protection Technology Co., Ltd., Qingdao 266071, China; \\ ${ }^{3}$ Beijing Advanced Innovation Center for Materials Genome Engineering, China Iron \& Steel \\ Research Institute Group, Beijing 10081, China; \\ ${ }^{4}$ School of Environment and Safety Engineering, Qingdao University of Science and Technology, \\ Qingdao 266042, China; \\ *E-mail: lixy@ cisri.com.cn and lijiarun@qust.edu.cn
}

doi: $10.20964 / 2021.05 .59$

Received: 6 January 2021 / Accepted: 16 March 2021 / Published: 31 March 2021

\begin{abstract}
In this work, a detection method of stray direct current on buried pipelines and a determination method for anodic/cathodic regions on pipelines is proposed. To compensate for the current interference, a current requirement test is adopted to provide a reference for an additional impressed current cathodic protection system. When the buried pipeline is severely disturbed, the implemented impressed current cathodic protection system, which is based on the results of the requirement test, negatively shifts the instant-off potential of the pipeline by at least $350 \mathrm{mV}$ during the measurement period. This shift meets the cathodic protection criteria, suggesting that the impressed current cathodic protection system can effectively suppress stray subway current-induced corrosion.
\end{abstract}

Keywords: Impressed current cathodic protection; Current requirement test; DC stray current; Drainage; Instant-off potential

\section{$\underline{\text { FULL TEXT }}$}

(C) 2021 The Authors. Published by ESG (www.electrochemsci.org). This article is an open access article distributed under the terms and conditions of the Creative Commons Attribution license (http://creativecommons.org/licenses/by/4.0/). 